\title{
Numerical Investigation of FRP-Strengthened CHS Columns
}

\author{
Themistoklis Tsalkatidis ${ }^{1, a}$ \\ ${ }^{1}$ Faculty of Science and Technology, Norwegian University of Life Sciences, Ås, Norway \\ athemistoklis.tsalkatidis@nmbu.no
}

Keywords: CFRP-jacketing, circular hollow steel sections, analytical investigation.

\begin{abstract}
The use of external CFRP jacket is examined as a retrofitting technique that improves the ductility and the load carrying capacity of the steel tube. The study focuses on the interaction between the steel and the jacket, which is treated as a contact problem. The contact conditions in the steelCFRP interface are represented by interface laws. Finite element modeling is used to simulate the physical problem and the results of the numerical analysis are presented and discussed. CFRP- jacket is proved to be an effective strengthening method for hollow steel columns.
\end{abstract}

\section{Introduction}

Nowadays, a high number of existing steel buildings must be repaired or strengthened due to deterioration, structural deficiency or even poor maintenance. There are many traditional and modern methods available to rehabilitate ageing building. A key retrofit technique that has been extensively used in reinforced concrete structures is the application of carbon fiber reinforced polymer (CFRP), usually in the form of external jackets providing a reversible and nondestructive retrofit option. CFRP is an advanced lightweight composite material that is corrosion resistant that has high stiffness to weight and strength to weight ratios. CFRP is adhesively bonded to the original structural element thus making its application easy to handle, quick and user friendly. This technique can also be applied in steel structures since it offers great advantages. Steel structural elements strengthened with CFRP remain lightweight, no weld-initiated stresses are present and the danger from corrosion is minimized. The main difference of steel to reinforced concrete elements, that are strengthened using CFRP, is their mode of failure. In steel elements, the dominant failure mode is the failure of the adhesive material itself, that connects steel and CFRP, whereas in reinforced concrete elements is the failure of the adherends [1]. Teng et al. [2] classify and review several proposed FRP strengthening techniques of steel structures and highlight their advantages and disadvantages. This paper aims to investigate the appropriateness of fiber reinforced polymer as a retrofitting technique in steel columns by exploiting and formulating the corresponding contact conditions. As a case study a circular hollow steel (CHS) column that is strengthened with a single- ply CFRP- jacket is used. A mathematical and a numerical approach of the problem are performed.

\section{Mathematical Approach}

Description. Contact problems are very complex in their nature, so it is a difficult task to find accurate solutions $[3,4,5]$. On the other hand, a theoretical- qualitative treatment is doable and provides a deeper understanding of the physical phenomena [6]. The case of a circular hollow steel tubular column under axial compressive force, that is strengthened using external single- ply CFRPjacketing around its periphery, is under study. Thin- walled members, such as hollow steel tubes, are susceptible to buckling due to their geometry. A high value of the $\mathrm{D} / \mathrm{t}$ (diameter- to- thickness) ratio of a long steel tube is an indication of such behavior as presented by Guo et al. [7]. Plastic strain formation in thin-walled structural elements is not significant and this lack is directly related to the presence of local buckling. Elephant's foot buckling, a form of outward circumferential buckling, near the bottom face of the column is the more common failure type found in hollow steel tubes under compression [8]. A way to prevent or delay this phenomenon is to strengthen the steel tube with CFRP- jacketing, as presented for circular hollow steel sections by Haedir and Zhao [9] and for SHS sections by Sundarraja et al. [10]. The use of Glass FRP- jacketing has also been examined by Teng 
and $\mathrm{Hu}$ [11]. The use of CFRP confines the tube and increases the axial load carrying capacity and the ductility of the steel member. Moreover, the endurance of the steel tube in environmental exposure is also significantly enhanced due to the outer layer of CFRP. Similar techniques have been used for the rehabilitation of steel beams [12] and deficient steel columns [13]. Batikha et al. [14] propose the use of FRP's as an effective way of preventing elephant's foot buckling in cylindrical shells.

Formulation. The problem under study is the investigation of the contact conditions that describe the composite behavior of a CFRP-strengthened circular hollow steel column. The theoretical approach used in thin- walled pressure vessels has been employed in the presented analysis. According to this theory, a vessel under pressure $\mathrm{p}$ is subjected to triaxial state of stress, as stresses develop in the circumferential or hoop $\left(\sigma_{1}\right)$, longitudinal $\left(\sigma_{2}\right)$ and radial direction $\left(\sigma_{3}\right)$. The values of the stresses are calculated using the Eqs. (1)- (3):

$$
\begin{aligned}
& \sigma_{1}=\frac{p R}{t} \\
& \sigma_{2}=\frac{p R}{2 t} \\
& \sigma_{3}=p
\end{aligned}
$$

If the pressure vessel is thin, that is the $\mathrm{R} / \mathrm{t}$ (radius to thickness) ratio is above 10 the radial stress can be ignored, as in our case. The same ratio $\mathrm{R} / \mathrm{t}$ affects the value of the two other stresses. Since $\mathrm{D}=2 \mathrm{R}$, then a higher value of $\mathrm{D} / \mathrm{t}$ ratio results in higher stresses.

For the case of the strengthened steel tube, the lateral expansion of the inner steel tubular part pressures the outer CFRP part, through the layer of the adhesive epoxy. In other words, the two parts are 'glued together' due to the action of the adhesive and this composite section is treated as an adhesive contact problem. The external CFRP- jacket is assumed to confine the steel tube as the pressure vessel confines its content. In the tangential to the steel- CFRP interface direction, where adhesion is considered, the tangential contact stresses represent the circumferential stresses of the thin- walled pressure vessel. In the normal to the steel- CFRP interface direction the interaction between the two parts is considered negligible. This refers to the radial stresses of the thin- walled pressure vessel being trivial comparing to the stresses that develop in the other directions. In the presented analysis, a constant CFRP thickness is considered and the effect of the different fiber orientation has not been examined. Fibers orientated only lateral to the column axis due to the use of hoop CFRP sheets are taken into consideration. The CFRP jacket is made of one ply. The periphery and the total height of the circular column are both covered with a CFRP jacket.

Let us now consider the CFRP sheet as a plate of thickness $t$, length $s$ and width $a$. The distance between the steel tube and the CFRP sheet is defined as $\mathrm{h}$ (gap) and K is plate's rigidity. An elastic and an adhesive part compose the total energy of this system [6]. The total energy $U$ of the problem is given by the following formula:

$$
\mathrm{U}=3 \mathrm{Kah}^{2} / 2 \mathrm{~s}^{3}+2 \gamma \mathrm{sa}
$$

where the first ratio is the elastic energy and the second part is the adhesive energy. The surface energy of the material is represented by $\gamma$. The surface energy used in the formulas is the relative surface energy, which is the average of the surface energies of the two bodies.

Since the column is circular $\mathrm{a}=2 \pi \mathrm{R}$, we obtain:

$$
\mathrm{U}=3 \mathrm{Kah}^{2} / 2 \mathrm{~s}^{3}+4 \gamma \pi \mathrm{Rs}
$$

According to JKR-Theory [6], the adhesive force $\mathrm{F}_{\mathrm{A}}$ for elastic deformable bodies is equal to $3 \pi \gamma \mathrm{R}$. Therefore, the total energy of the system yields to:

$$
\mathrm{U}=3 \mathrm{Kah}^{2} / 2 \mathrm{~s}^{3}+4 \mathrm{~s} \mathrm{~F}_{\mathrm{A}} / 3
$$


Equation (6) depicts the connection between the adhesive force $\mathrm{F}_{\mathrm{A}}$ and the total energy of the system U. The problem under investigation, as described before, has been treated as an adhesive contact problem where only tangential loading is present. In practice, the inner steel tubular section and the outer CFRP jacket are 'glued together' due to the action of the epoxy resin.

\section{Application}

Numerical model. A three- dimensional finite element model of a circular hollow steel tube that is strengthened with a single- ply CFRP- jacket has been created using the ANSYS software program [15-19]. The model has been validated by comparison to results from the international literature [9] and the results are in close agreement. The CFRP- jacket covers the whole height of the steel tube and it is placed externally. The dimensions of the steel tube are 168.3 by 5 by $1000 \mathrm{~mm}$ and the jacket is $0.25 \mathrm{~mm}$ thick [19]. The finite element grid is depicted in Fig.1.

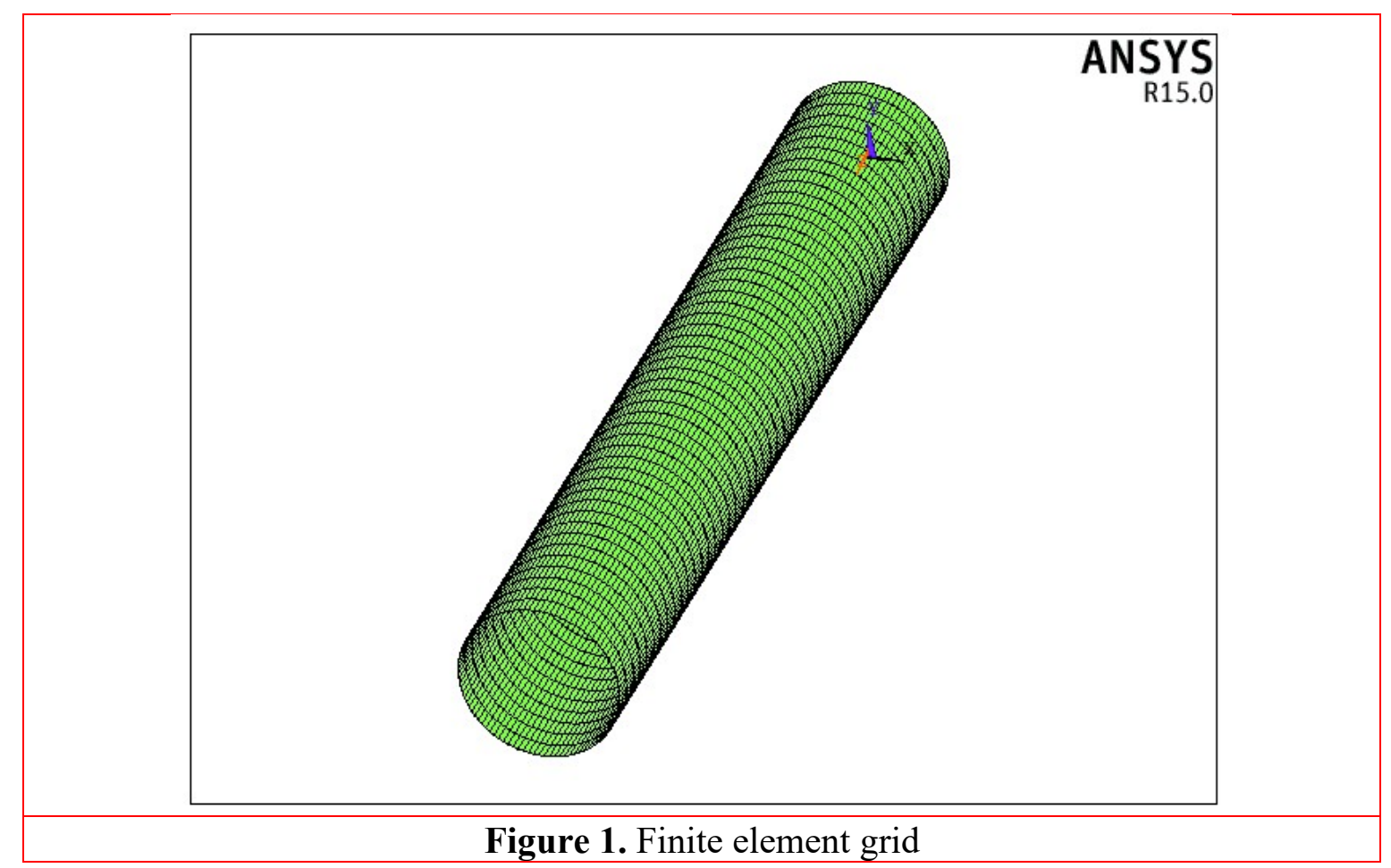

A structural shell element has been selected for both the steel tube and the CFRP. The chosen three-dimensional eight-node shell element has six degrees of freedom (three displacements and three rotations about the $\mathrm{x}, \mathrm{y}$, and $\mathrm{z}$ axes) at each node and its characteristics include plasticity, ability to develop great deformations and displacements, creep and hardening.

The adhesive epoxy used to glue the two adherends (steel and CFRP) together, has been modelled using interface elements contact elements. All the bodies in contact have been regarded as deformable. The contact elements overlay the structural shell elements used for the simulation of the adherends. They are located at the interface between steel and CFRP and have the material properties of the epoxy adhesive.

The numerical analysis that is performed can be classified as geometrically nonlinear with stress stiffening, large deflections and small strains characteristics. ANSYS program uses the Newton-Raphson method as an incremental-iterative solution procedure [18].

Material laws. The constitutive material law used for steel in the analysis is bilinear elastoplastic-strain hardening using the von Mises stress yield criterion. The yield stress of the steel has been set equal to $355 \mathrm{MPa}$ and the modulus of elasticity to $210 \mathrm{GPa}$. The Poisson ratio of steel has been assumed as 0.3. For the CFRP- jacket and the adhesive epoxy, a non-linear material law has been implemented. The yielding strength of CFRP has been determined at $1800 \mathrm{MPa}$ and the modulus of elasticity at $165 \mathrm{GPa}$. For the contact elements, that represent the adhesive epoxy, the material 
properties of epoxy have been applied. The ultimate tensile stress has been determined at $30 \mathrm{MPa}$ and the modulus of elasticity at $4 \mathrm{GPa}$. The Poisson ratio has been assumed to be 0.38 .

Support and loading conditions. The supports of the steel tube have been simulated as pinned. The translations about all the axes have been restrained at the bottom. At the top end of the steel tube only the translation along the $\mathrm{z}$ - axis has not been restrained. Regarding the loading conditions, a compressive static load has been applied at the top end in multiple small steps in order to avoid local failure at the initial stages of the numerical analysis.

\section{Results}

The following Figs. 2-7 present the results of the computational analysis. The deformed shape of the unstrengthened steel circular tube is depicted in Figure 2 and of the strengthened one in Figure 3.

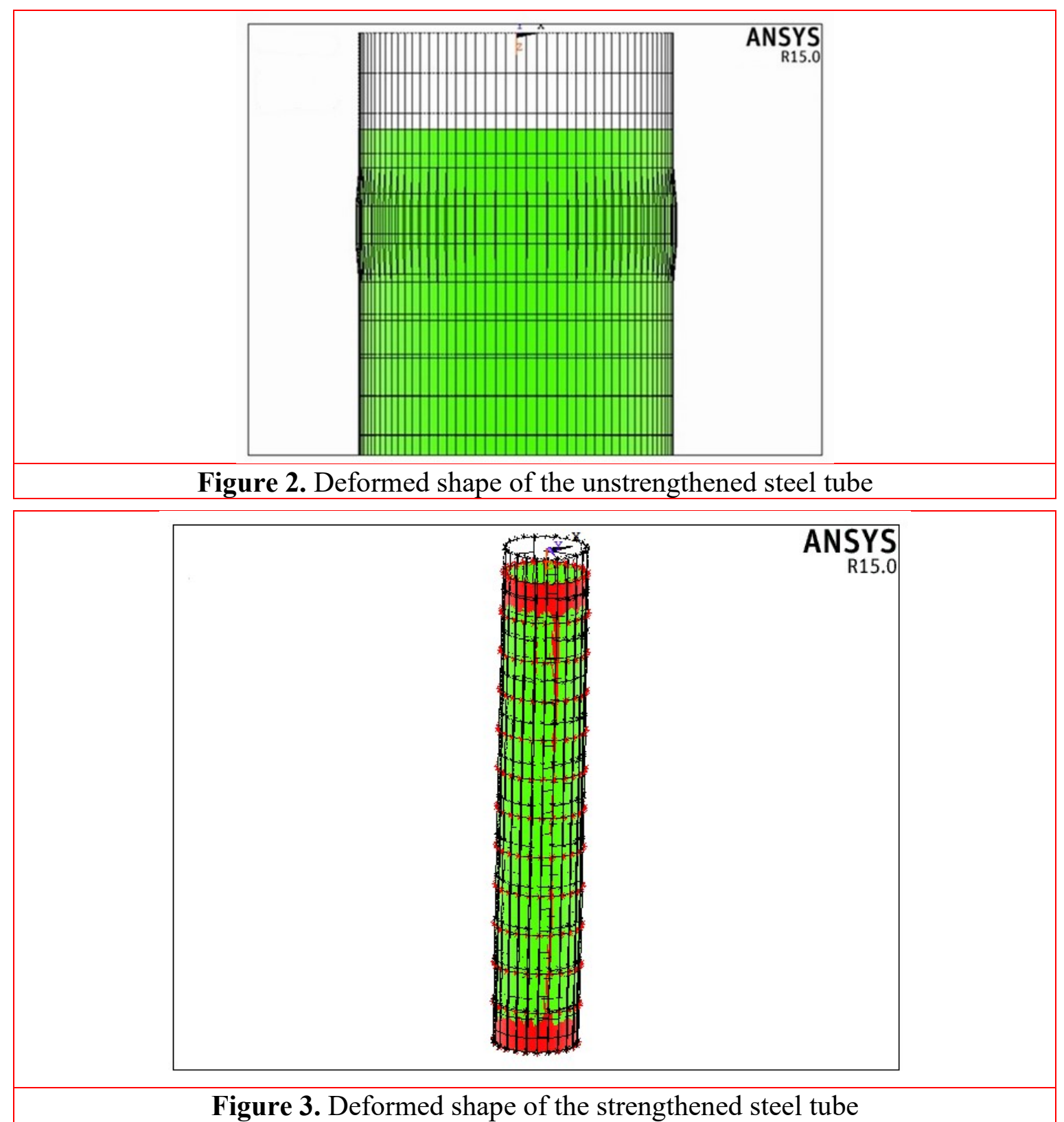

The buckling load for the bare steel tube and the strengthened one has been found equal to $907 \mathrm{kN}$ and $963 \mathrm{kN}$, respectively. The axial shortening of the strengthened steel column is equal to $1.519 \mathrm{~mm}$ at maximum load and it is depicted in Fig. 4. The von Mises stress and von Mises strain variations are plotted in Figs. 5 and 6. 

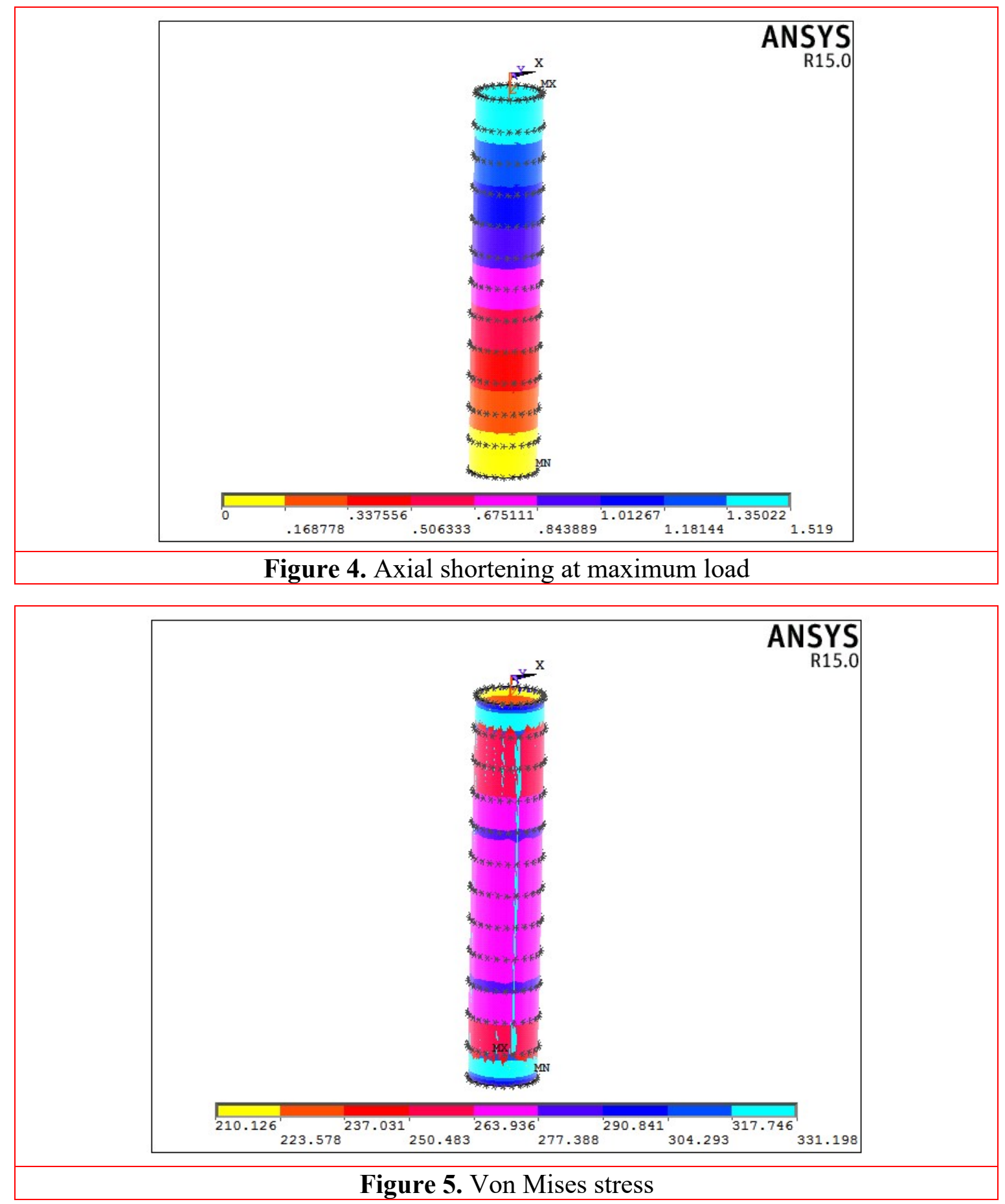


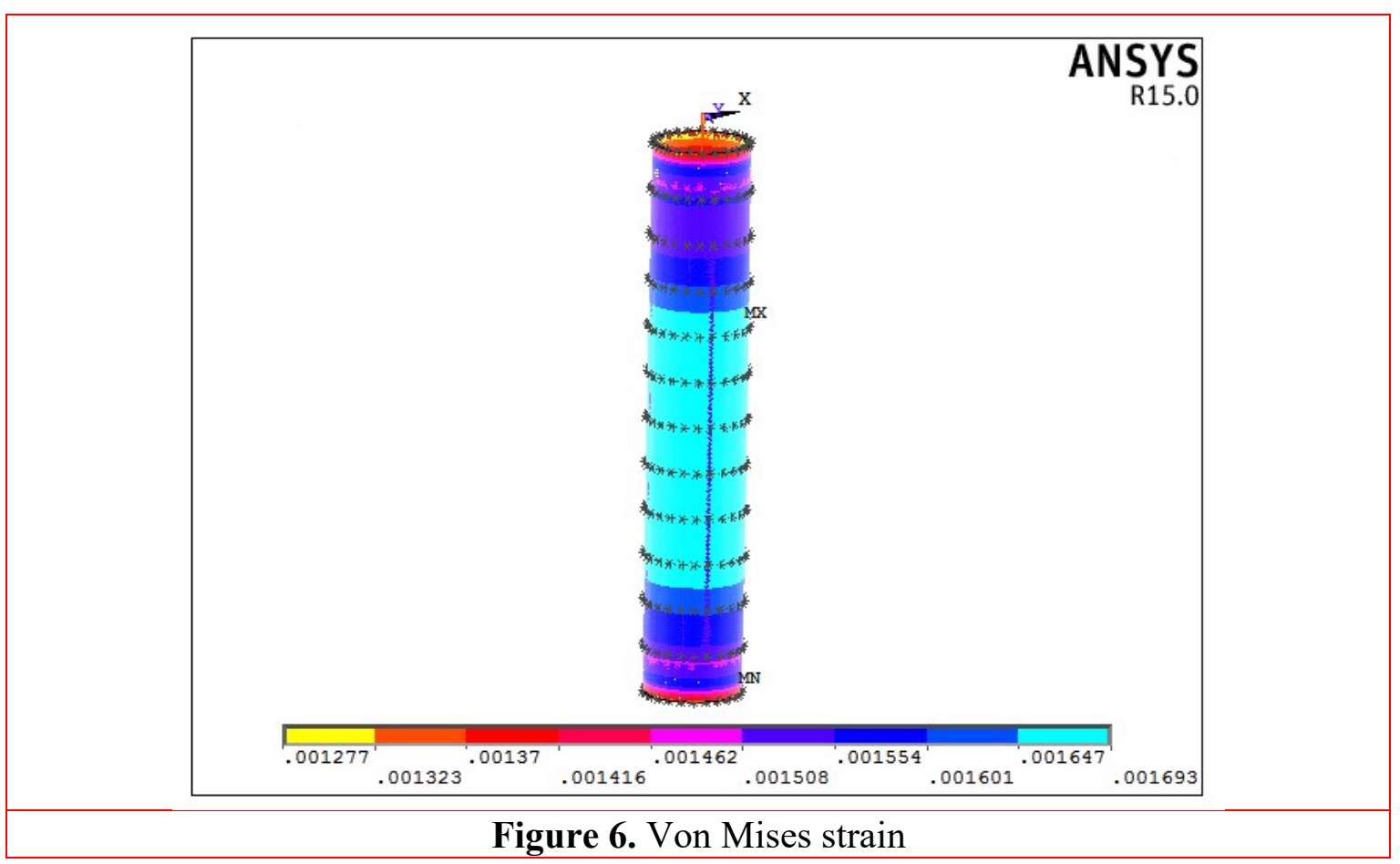

The comparison between the load- axial shortening curves of the bare steel and the strengthened steel column is shown in Fig. 7.

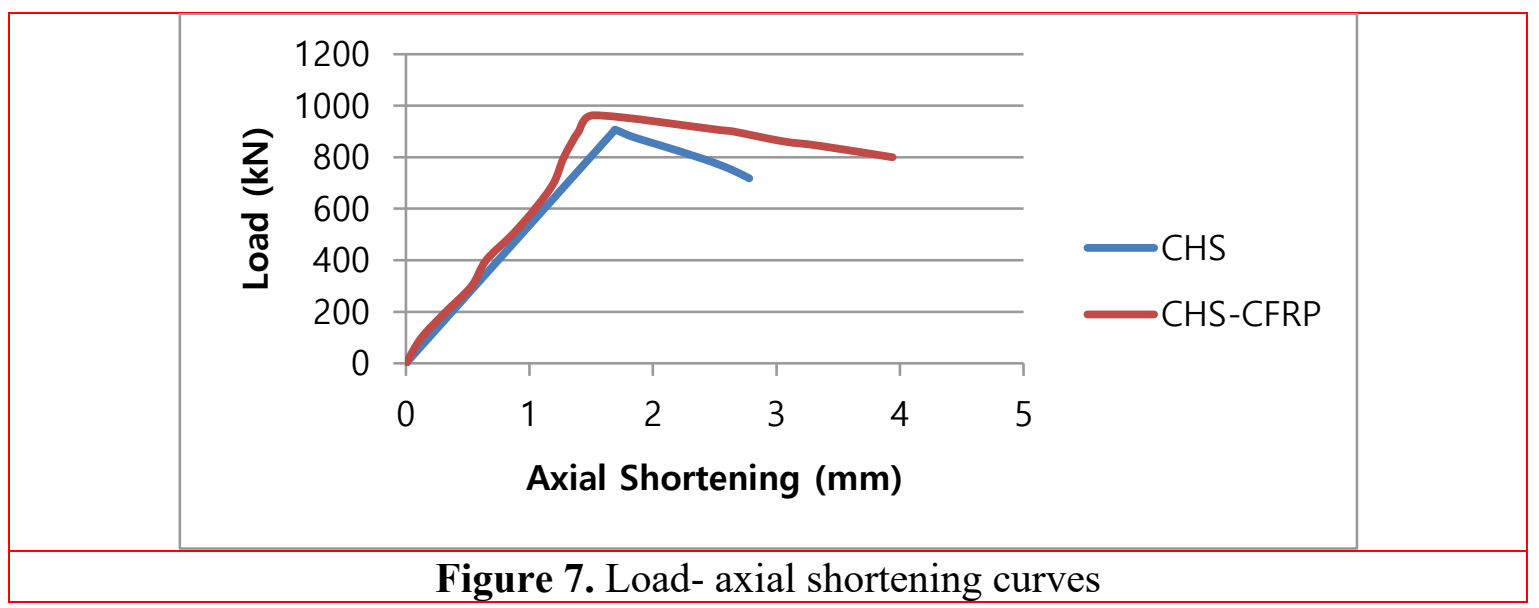

\section{Discussion}

The interpretation of the numerical results leads to the following observations:

- The adhesive forces are calculated by multiplying the adhesive stresses with the thickness of the structure. Therefore, the contribution of both the thickness of the steel tube and the thickness of the CFRP is significant. For a given diameter or width, the thickness of the steel tube is decisive for the measure of the adhesive forces. The number of the layers used is directly related to the thickness of the CFRP- jacket. Recent studies have found that using more than three layers does not contribute significant in gaining strength (Teng et al., 2012).

- The different orientation of the carbon fibers in multiple layers has not been examined in the current analysis. Fibers orientated only parallel to the column axis due to the use of longitudinal CFRP sheets have been considered.

- The failure of the strengthened column is due to rupture of the CFRP- jacket because of excess outward buckling. No adhesive failure was recorded. 
- The initial geometrical imperfections during the manufacturing of the hollow steel tube, have not been taken into consideration in the analysis, since its effect is not significant for thinwalled steel tubes with relatively small $\mathrm{D} / \mathrm{t}$ ratios.

- An increase of the ultimate load carrying capacity of $6.2 \%$ and of the ductility of $41.7 \%$ has been calculated in the strengthened steel section in comparison to the bare steel one.

\section{Conclusions}

An analytical formulation and a numerical simulation for predicting the response of a strengthened circular steel hollow column using external CFRP- jacket have been proposed in this study. The conclusions of this investigation are presented:

- CFRP-jacketing of steel elements is a promising technique and it can be used for enhancing the performance of structural members under seismic loading conditions where gain in ductility and energy absorption is important.

- The theory of thin walled vessels can only be employed if the internal pressure exceeds the external one, such in the case of outward buckling. Therefore, the inward buckling of the column cannot be examined using this theory.

- The contribution of the CFRP- jacket in delaying the outward buckling of the steel tube is high. On the contrary, for the case of the inward buckling this contribution is relatively small. In general, the use of CFRP- jacketing as retrofitting technique in structural steel elements is highly recommended since both the load carrying capacity and the ductility of the strengthened elements is enhanced.

\section{Conflict of Interest}

The author declares no potential conflicts of interest that may be perceived as inappropriately influencing the representation or interpretation of reported research results.

\section{References}

[1] Y. Yu, Strengthening of Steel Structures, Lambert Academic Publishing, Saarbrücken, Germany, 2011.

[2] J.G. Teng, T. Yu, D. Fernando, Strengthening of steel structures with fiber-reinforced polymer composites, Journal of Constructional Steel Research 78 (2012) 131-143.

[3] K.-J. Bathe, Finite Element Procedures, Prentice Hall, New Jersey, NJ, USA, 1996.

[4] E.S. Mistakidis, G.E. Stavroulakis, Nonconvex optimization and its applications: Nonconvex optimization in mechanics, Kluwer Academic Publishers, Dordrecht, Netherlands, 1998.

[5] T. Tsalkatidis, A. Avdelas, The unilateral contact problem in composite slabs. Experimental study and numerical treatment, Journal of Constructional Steel Research 66 (2010) 480-486.

[6] V.L. Popov, Contact Mechanics and Friction, Springer-Verlag, Berlin, Germany, 2010.

[7] L. Guo, Y. Liu, H. Jiao, et al., Behavior of thin-walled circular hollow section stub columns under axial compression, Journal of Constructional Steel Research 16 (2016) 777-787.

[8] Eurocode 3, Design of Steel Structures. Part 1.1: General Rules and Rules for Buildings, European Committee for Standardization, Brussels, Belgium, 2005.

[9] J. Haedir, X.-L. Zhao, Design of short CFRP-reinforced steel tubular columns, Journal of Constructional Steel Research 67 (2011) 497-509.

[10] M.C. Sundarraja, P. Sriram, G. Ganesh Prabhu, Strengthening of hollow square sections under compression using FRP composites, Advances in Materials Science and Engineering, (2014) Article ID 396597 doi:10.1155/2014/396597. 
[11] J.G Teng, Y.M. Hu, Behaviour of FRP-jacketed circular steel tubes and cylindrical shells under axial compression, Construction and Building Materials 21 (2007) 827-838.

[12] M.A. Youssef, Analytical prediction of the linear and nonlinear behavior of steel beams rehabilitated using FRP sheets, Engineering Structures 28 (2006) 903-911.

[13] M. R. Ghaemdoust, K. Narmashiri, O. Yousefi, Structural behaviors of deficient steel SHS short columns strengthened using CFRP, Construction and Building Materials 126 (2016) 1002-1011.

[14] M. Batikha, J.F. Chen, J.M. Rotter, et al., Strengthening metallic cylindrical shells against elephant's foot buckling with FRP, Thin-walled Structures 47 (2009) 1078-1091.

[15] T. Tsalkatidis, Numerical simulation and analytical study of glulam timber beams, International Journal of Engineering and Technology 3 (2014) 129-136.

[16] S. Moaveni, Finite Element Analysis: Theory and Application with ANSYS, Prentice Hall, New Jersey, NJ, USA, 1999.

[17] S. Fawzia, K. Shahanara, Finite element analysis of CFRP strengthened steel hollow sections under tension, Advanced Steel Construction 10 (2014) 463-475.

[18] ANSYS User's Manual, ANSYS Inc., PA, USA, 2015.

[19] T. Tsalkatidis, Strengthening of circular and square hollow steel tubes under axial compression using CFRP- Jacketing, EMI International Conference, Metz, France, 25-27 October 2016. 